\title{
The Detection of Ichthyophonus hoferi in Naturally Infected Fresh Water Ornamental Fishes
}

\author{
Mahsa JafariZadeh"*, Rahim Peyghan² and Shadi Eftekhar Manavi² \\ ${ }^{1}$ Fisheries Department, Islamic Azad University, Ahvaz Branch, Ahvaz-Iran, Iran \\ ${ }^{2}$ Veterinary Faculty, Shahid Chamran University of Ahvaz, Ahvaz, Iran
}

\begin{abstract}
Ichthyophoniasis is one of the most important systematic infections among different species of fishes that caused by Ichthyophonus hoferi. In the present study, we have reported this parasite from two species of ornamental fish, black tetra (Gymnocorymbus ternetzi) and tiger barb (Pentius tetrazona) in Ahvaz-Iran. Examined fishes had marked signs such as abnormal swimming, lethargy, swelling abdominal and low rate mortality. In this study, the two phases of life cycle of $I$. hoferi involving active and passive detected. The obvious internal sign was white cysts and nodules, which embedded in infected spleens. The cysts were full of schizonts that were surrounded by collagen fibers and many eosinophilic cells. Plasmodium spherical bodies with variable sizes were detected by microscopic examination of wet mount squash from the infected organs. In addition, histopathology studies showed that there were many granulation tissues surrounded by multilayer connective tissues in the infected tissues. Tissue samples were also isolated and put in to Minimum Essential Medium (MEM) to detect the germination of Ichthyophonus hofer for distinguish Ichthyophoniasis from Mycobacterial infections.
\end{abstract}

Keywords: Ichthyophonus hoferi; Ornamental fishes; Black tetra; Tiger barb; Histopathology; Nodules; Spleen

\section{Introduction}

Ichthyophonus hoferi was first identified in cultured brown and brook trout in Germany by von Hofer in 1893. The protozoan nature of $I$. hoferi described and named by Plehn and Mulsow in 1911 as a fungus. Ultimately this parasite classified into Mesomycetozoea [1-3]. Signs are species-related and depend on the condition of individual fish. Ichthyophonus hoferi causes a systematic granulomatous infection in their hosts. I. hoferi has produced infections in many different species of freshwater, estuarine, marine teleosts and adapt to a wide range of environmental conditions [4]. Ichthyophonus sp. has been reported from many temperate and some tropical waters. Couch in 1985 detected two cases of fishes, sea catfish, and spot, infected by $I$. hoferi in Gulf coast. For the first time Ichthyophonus sp. is reported in two cultured marine fish including Mugil capito and Lia salines from Spain [5]. This disease has records from over 80 species of both marine and freshwater fishes and results into mass mortalities and economic losses [6]. This parasite detected in several commercial fish [7]. In the case of aquarium fish, Ichthyophonus hoferi reported in sumatra barb (Systomus tetrazona) and black tetra (Gymnocorymbus ternetzi) by Reichenbach-Klinke, $\mathrm{H}$ in 1954 and 1955. Ozturk et al. in 2010 screened this pathogen in some organs of goldfish (Carassius auratus). Discus fish (Symphysodon.spp) is the new host record of ornamental fish that infected by I. hoferi [8]. I. hoferi reported in herring in the northwest Atlantic (up to 25\% infection) with associated reductions in the population, up to $10 \%$ infection in U.K waters with mortality, and mackerel up to $69 \%$ infection and haddock up to $80 \%$ infection [9]. There are many reports that I. hoferi causes mortality in post-smolts of Atlantic salmon and Chinook salmon [10,11]. The purpose of the present study is the description of the morphology and pathology of $I$. hoferi as found in two species of ornamental fish in Iran.

\section{Case Presentation}

In a disease case, from a local aquarium fish propagation center, the culture facility with the size of $40 \mathrm{~cm}$ in length and $30 \mathrm{~cm}$ in width was regarded because of swimming disorders of one the black tetra
(Gymnocorymbus ternetzi) and swollen abdominal of one tiger barb (Pentius tetrazona). This aquarium, involved 35 adult fish from both species. This facility was filled with closed systems water, tap water, of Ahvaz city. As a random seven fishes from both species, five black tetra and two tiger barb were collected. After anesthesia, the fishes were killed, and total length and total weight of the fishes were measured and recorded. Tiger barbs had average length of $5.2 \pm 1.2 \mathrm{~cm}$ and average weight of $1.5 \pm 0.5 \mathrm{~g}$. The black tetras average length was $5.3 \pm$ $0.8 \mathrm{~cm}$ and average weight was $2.5 \pm 0.3 \mathrm{~g}$. All organs were examined by routine clinical methods. Within examination the pericardial cavity, many visible white nodules were seen in spleens of the studied fishes. In addition, one specimen had some nodules in heart organ.

\section{Microscopic examination}

Wet and dry smear were prepared from spleen tissues and the dry smears were stained with Giemsa staining.

\section{Tissue culture}

Samples from infected tissues were taken and incubated in MEM medium (Eagle's minimum essential medium supplemented with $10 \%$ fetal bovine serum, $100 \mathrm{IU} / \mathrm{ml}$ penicillin, and $100 \mathrm{mg} / \mathrm{ml}$ streptomycin). Cultures were incubated in $25^{\circ} \mathrm{C}$ and the tissue cultures were examined every day under microscope. Eventually after 2 weeks, the tissue dry smear was prepared and stained by Giemsa method.

*Corresponding author: JafariZadeh M, Fisheries Department, Islamic Azad University, Ahvaz Branch, Ahvaz-Iran, Iran, Tel: 989163128034; E-mail: jafarizadeh.mahsa@gmail.com

Received October 12, 2014; Accepted November 07, 2014; Published November 12, 2014

Citation: Zadeh MJ, Peyghan R, Manavi SE (2014) The Detection of Ichthyophonus hoferi in Naturally Infected Fresh Water Ornamental Fishes. J Aquac Res Development 5: 289. doi:10.4172/2155-9546.1000289

Copyright: $\odot 2014$ Zadeh MJ, et al. This is an open-access article distributed under the terms of the Creative Commons Attribution License, which permits unrestricted use, distribution, and reproduction in any medium, provided the original author and source are credited. 
Citation: Zadeh MJ, Peyghan R, Manavi SE (2014) The Detection of Ichthyophonus hoferi in Naturally Infected Fresh Water Ornamental Fishes. J Aquac Res Development 5: 289. doi:10.4172/2155-9546.1000289

\section{Histopathological sampling and examination}

Samples from heart, liver, intestine, gonads and spleen were cut and fixed in $10 \%$ phosphate-buffered formalin for histological examination. By using standard techniques, samples were processed and then sections stained either in haematoxylin-eosin [12] and Periodic Acid-Schiff. Micrometric measurement was carried out using Sa-Iran camera microscope and Axio-vision software.

\section{Results}

Infection to Ichthyophonus hoferi was found in internal organs of all examined aquarium fishes including five black tetra and two tiger barb. During gross examination, white nodules were found on spleen organs of both fish species. In one specimen (tiger barb), some nodules were also seen in heart organ. However, no external sign of infection was observed on the body surface of naturally infected fishes. The morphology and developmental stage of life style of $I$. hoferi were similar in both specimens. Schizonts of Ichthyophonus hoferi were the most commonly characteristic of squashed infected organs. The size of the schizonts, include the wall varied from $54 \mu \mathrm{m}$ to $182 \mu \mathrm{m}$ in all of specimens (Average 85.10). Differences between schizonts size indicate that, the schizonts of black tetras were bigger compare to the tiger barbs. Microscopic examination of wet mount squash of infected organs were represented, thick walled spherical bodies (resting schizonts) (Figure 1). The subdivision of the contents of each of the spherical bodies results to produce small uninucleate stages. The reason for this incident is rotational movement in the wall of spherical body (Woo and Btuno 2006). By studying the histopathological sections encapsulated and un-encapsulated schizont inside well-defined host cellular granulomas were observed. In some cases encapsulated schizont consist of 3-5 fibrous layers or fibrotic capsule that related to the passive phase and, some nodules had thin fibrotic layer, which represented active phase (Figure 2). In addition, the Hydropic degeneration observed in the infected spleen. Detected black spots (melanin reaction) around schizonts had different sizes from $6.77 \mu \mathrm{m}$ to $2.49 \mu \mathrm{m}$ (average $4.57 \mu \mathrm{m}$ ) in infected spleen. After incubation in Minimum Essential Medium, the germination of the infective agent and formation of new budding yeast of plasmodium, non-septate germination tubes and terminating club-shaped cells from Ichthyophonus schizonts, were seen. (Figures 3-5). Then the two plasmodia free within the tissue and migrating away from an empty schizonts (Figure 3). Histopathologic examination of the lesion of spleen showed the presence of characteristics granuloma. The granuloma consists of resting schizonts surrounded by eosinophilic leucocyte infiltrations. The microscopic examination of schizonts in

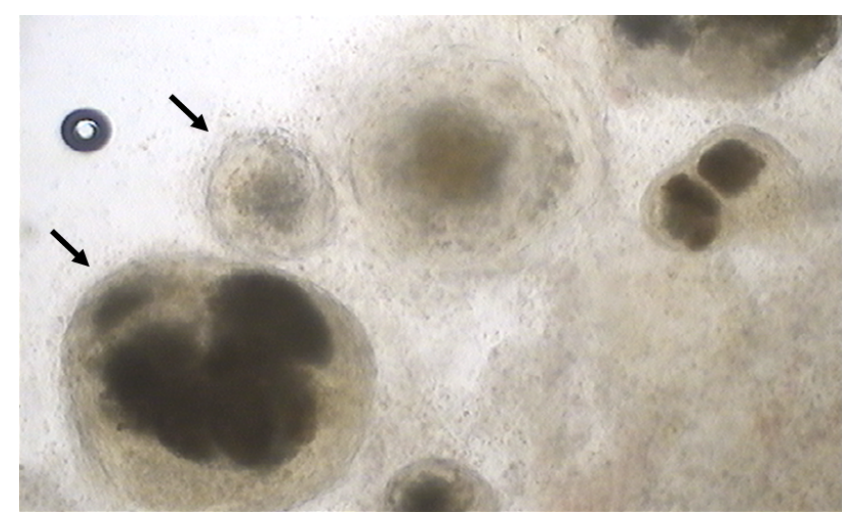

Figure 1: Squash preparation from nodules showing thick walled resting schizont in naturally infected tiger barb, spleen, x100 magnification.

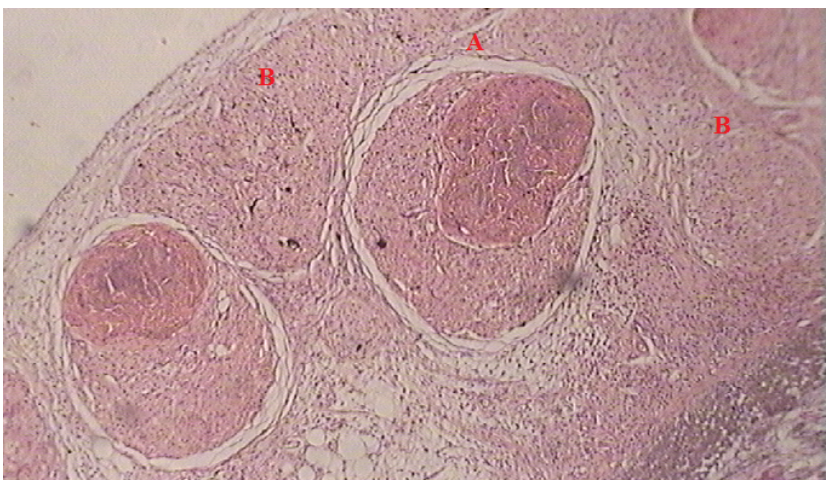

Figure 2: A. Encapsulated schizonts. B. Un-encapsulated schizonts, inside well-defined host cellular granulomas in naturally infected tiger barb, spleen, x40 magnification.

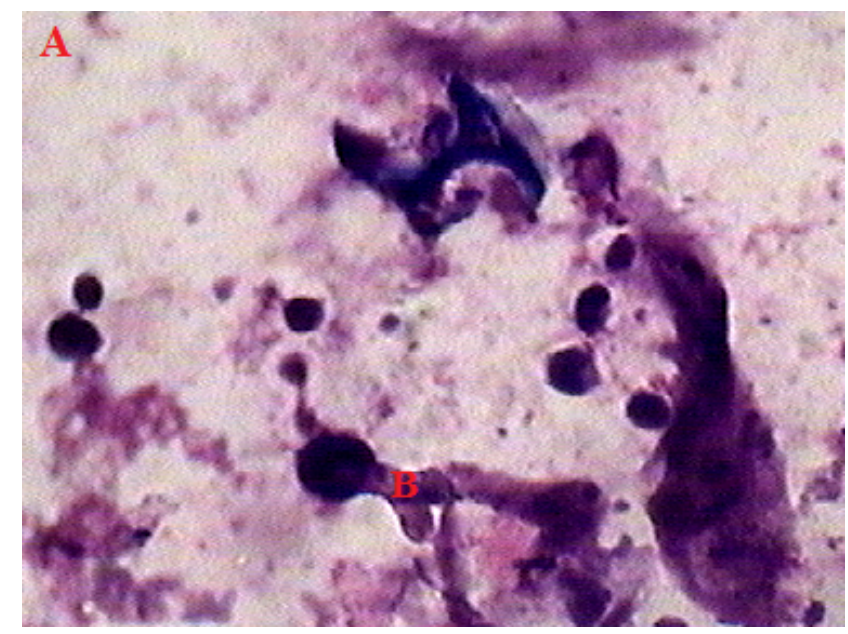

Figure 3: A. Plasmodium. B. Existing a collapsed Ichthyophonus hoferi schizonts with two plasmodia. Culture media (MEM). Black tetra, spleen, x400 magnification.

black tetras showed the black spots or melano-macrophage centers. Although, these melanized centers were not seen in all examined tiger barbs. In addition, the outer walls of schizonts represented the strong Periodic Acid Schiff (PAS) positive staining reaction.

\section{Discussion}

In this study, samples from naturally infected two species of ornamental fishes, black tetra and tiger barb, were studied and screened. The result of our study demonstrated that the fishes were suffered from Ichthyophoniasis. This disease is more frequently see in marine fishes. However the studied fishes were freshwater species, but they may have been feed by contaminated marine food. As this substantially differs between different host species, obvious signs of disease may considerably differ among fish species [13]. This parasite by means of blood stream or lymphatic system, engaged to all parts of host body especially blood rich organs such as liver, heart or spleen [11]. Spherical, thick-walled, and plasmodium is a commonly internal sign of infection by $I$. hoferi. In addition, non-specific signs may emerge. These signs involve behavioral changes and changes associated with organs such as swimming abnormalities and loss of pigment control. Other signs were lethargy, fluid accumulation, abdominal distension, or enlargement of organs, wasting of body musculature, skin roughening, and increase 


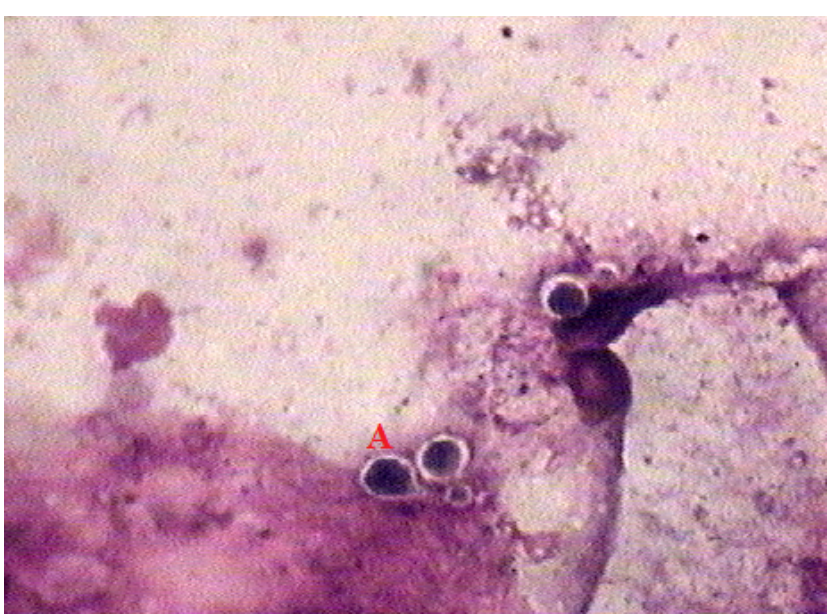

Figure 4: A. Terminating club-shaped cells. Culture media (MEM). Black tetra, spleen, x400 magnification.

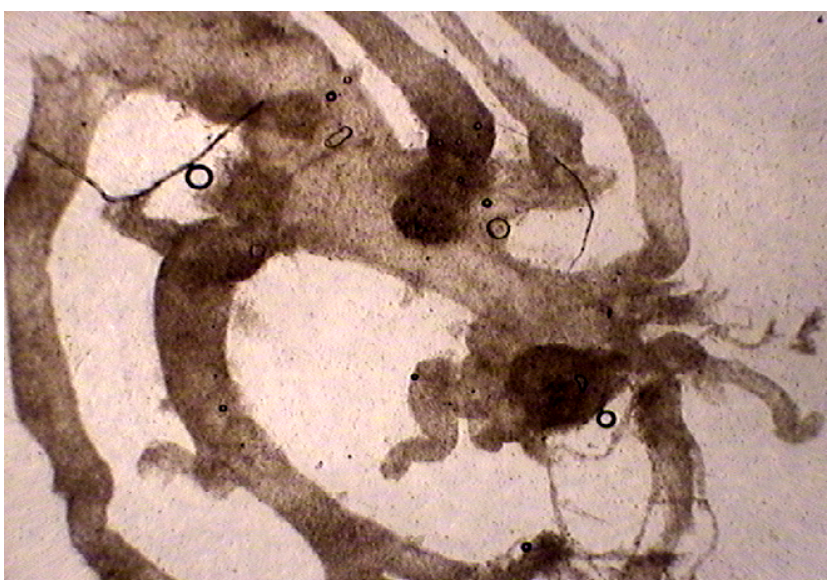

Figure 5: Non septate germinating tubes from a schizont in culture media (MEM). Black tetra, spleen, x40 magnification.

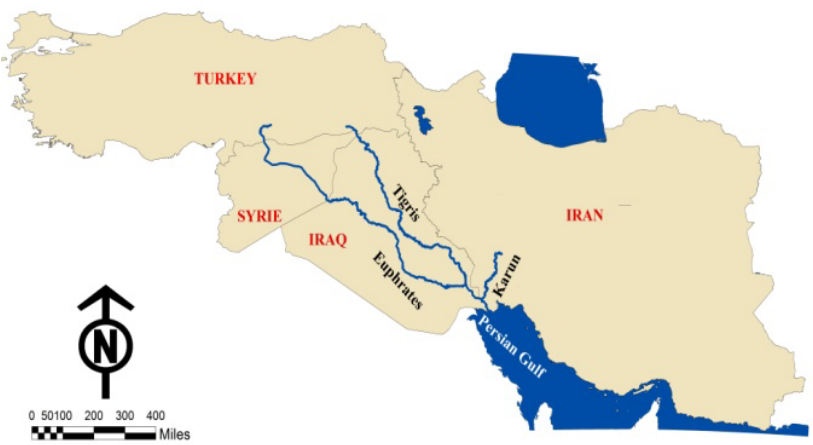

Figure 6: The position map of Rivers in two countries (Iran, Iraq), which, release into Persian Gulf.

in mortality [13]. In haddock [13], herring [14] and plaice [13,14], the most obvious lesions occurred in white muscle, heart, liver and kidney respectively. The signs of the examined fishes were swimming disorders, lethargy, swelling abdominal, and mortality. In all of studied fishes, nodulation was observed only in spleen organ. The host immunological reactions of the disease usually occurred in two phases involving acute and chronic [16]. In the case of acute, that reported in herring by Sindermann and Scattergood in 1954, the multiple germination of thick walled schizont, replacement of tissues by the parasites mass and gross external and internal signs such as roughened skin and nodules were seen. On the other hand, connective tissue encapsulation of schizont, and cell infiltration were detected in chronic phase. One of the characteristics of this parasite is sever response around the schizonts. The resting schizonts, could observe in tissues and appears roughly circular, thick fibrous wall. The pathological examination of this study showed the two form of schizonts including undeveloped and developed and defined by just one author, Hassan Rahimian (1998), as passive and active form of this parasite respectively. In active phase, the Pathogen grows and speared on the body of host with no or little microscopically reaction. On the other hand, single or multiple whitish nodules are observed in the passive form [16]. It is important to note that the active and passive related to parasite and the acute and chronic related to host. The undeveloped schizonts of I. hoferi surrounded by thick layers of fibrious host reaction. However the developing schizonts covered by thin fibrotic layers that demonstrate the rapid growth [16]. In the present study, related to the nodulation and body reaction, both phases, active and passive, were detected in tiger barb and black tetra respectively. These lesions usually consist of the granulomatous reaction surrounding single schizont or group of schizonts [11]. This study showed some melanin pigments in the schizont. Melanized centers usually represent in the form of nodular (Agius and Roberts 2003). In the late stage of chronic diseases response to tissue damages and cellular response such as Ichthyophonus these melanized centers emerge [17]. Agius in 1979b reported that the fishes who suffered from $I$. hoferi have been associated with raised pigment macrophage aggregates (PMA). Roberts in 1975 reported that the function of these black spot is deposition of pathogens including parasitic and bacterial spores. In addition, Agius [17] showed that these pigments play an antigen-processing role in immune response. In the present study, 84 per cent of 35 adult tiger barb and black tetra in target culture facility did not show any external signs in surface of body and muscles; however, this parasite engaged to inner organs of all examined fish.

In the early stages of infection, there is usually a marked inflammatory reaction surrounded by individual schizonts, which is followed by the deposition of a fibrous or connective tissue capsule [13]. By studying the histopathology slides, the reaction of host showed two different responses. The infected spleen of black tetras had encapsulated schizont with thick layers of fibrous reaction. However, the encapsulated schizonts in the spleen of tiger barbs represented thin layers of fibrotic reaction. On the other hand, sometimes there is no reaction around the schizonts. In this situation the un-encapsulated schizont were emerge. There have been some suggestions for the ways of natural transmission of I. hoferi infections among marine fishes that may occurred by ingestion of infected food (especially fish) or directly from the water [11]. By ingestion of resting schizont or latent cysts that transformed into germ-tubes or hyphae, the natural transmission is creating. Then the amoebolasts produce and penetrate into the intestine wall and transported in blood to the viscera where they change in to uni- or binucleate cysts and then the multinucleate cysts grow. Although, in this study, the way of transmission is not clear, some possibility ways are including infected facility, fishes, or water. Although, there is a more possibility that polluted water of Ahvaz city is the suspected factor to spread of I. hoferi in our region. Five stages in life cycle of this parasite have been detected including Plasmodial 
bodies, multinucleated cysts, resting schizont, germinating resting schizonts and conidial elements [18]. After opening the viscera of infected fishes, just two stage, resting schizont and multinucleated cysts, were seen. One of the important stages of identification this parastite is germination of schizonts. For this reason, this parasite grew in MEM. In this case, Non septate germination tubes emerge when the host dead in culture. The last stage (conidial elements), which we did not see, always occurs accomplished with tissue necrosis [19] and hyperplasia [20]. The inside of the schizonts represented PAS positive reaction that is an evidence of vacuoles storing polysacharids [16]. As we mentioned before by implementing the PAS staining, one way of confirmation this type of parasite, the walls showed positive reaction. The first report of Ichthyophoniasis in wild and cultured sea bass reported in 1990 by Sitja-Bobadilla and Alvarez-Pellitero. Rand and Cone [4] reported the highest numbers of lesions were associated with the liver, spleen, and kidneys of infected trout and ranged from one to a few focal, creamy white patches at the end of week two, too many confluents at the end of week six in experimentally infected rainbow trout. Donaldson [21] suggested that the absence of elevated cortisol levels show that there is only a limited stress response period of $I$. hoferi in rainbow trout. However, Rand and Cone [4] suggested that cortisol elevation might not be component of the host response to the natural disease process. Spanggaard and Huss [23] showed that different types of development of Ichthyophonus could be triggered by changes in important factors of water such as $\mathrm{pH}$, temperature, salinity, and carbon dioxide tension. Spherical cell or often called the resting schizonts is the most commonly detected stage of the parasite and has thick-walled and surrounded with fibrous reaction tissue. Most or all of the pathogenesis of Ichthyophonus can be directly linked to the replacement, disruption, and atrophy of infected tissues by the proliferation of the parasite. In some cases, tissues of normal organs are almost completely replaced. In this study, the vacuolation and fragmentation of schizont cytoplasm were observed. This incident is occurred because of the loss of integrity of schizont walls and lack of distinction between schizont organells. As a result, the vaculation were represented [13]. No tissue has found to be immune from infection by I. hoferi. However, some organs that have high blood supply seem to be more susceptible affect compare to the other organs [23]. A survey that conducted in Al-Madaen drainage network showed that L.abu is one of the host native species of this parasite [24]. Similarly, Mansor et al. [25] reported one case that infected by $I$. hoferi among five different species in Tigris River - Iraq.

It is obvious that the aquarium industry is becoming the popular entertainment in all parts of the world and increase significantly in different countries, for this reason, Ahvaz city do not except from this kind of industry. Export and import of ornamental fishes from different countries may lead to the outbreaks of different types of infections. Since, the number of species that introduce to Iran is impressive, it is inevitable to face with numerous diseases. While some portion of sewage system, have been released into the Karun River that located in Ahvaz city, the spread of pathogens from the water of aquarium and ornamental fishes to native fishes is more probability. As we mentioned before, this parasite was reported in native fishes of Tigris River in Iraq, Iran's neighborhood. Tigris and Euphrates Rivers, from Baghdad and Karun, from Ahvaz join in Arvand Rud, then release into Persian Gulf (Figure 6). As a result, it is more likely to expand the pathogen from infected fishes and water from rivers of Iraq and Iran to native fishes of Persian Gulf. Overall, the main source of Ichthyophonus hoferi in these two fresh water ornamental fish is not clear. This important disease has reported in many regions in the world, although in our country there is no report of Ichthyophoniasis from native, cultural, and ornamental fishes. It can be regarded as first report in Iran.

\section{Acknowledgment}

I would like to say my appreciation to all those who supported me especially my sister Bahar and also thanks to diagnostic laboratory staff for preparation of histopatholgic sections.

\section{References}

1. Ragan MA, Goggin CL, Cawthorn RJ, Cerenius L, Jamieson AV, et al. (1996) A novel clade of protistan parasites near the animal-fungal divergence. Proc Natl Acad Sci USA 93: 11907-11912.

2. Mendoza L, Taylor JW, Ajello L (2002) The class Mesomycetozoea: a heterogeneous group of microorganisms at the animanl-fungal boundary. Annu Rev Microbiol 56: 315-344.

3. Kocan RM (2013) Proposed Changes to the Nomenclature of Ichthyophonus sp. Life-Stages and Structures. J Parasitol 99: 906-909.

4. Rand TG, Cone DK (1990) Effects of Ichthyophonus hoferi on condition indices and blood chemistry of experimentally infected rainbow trout (Oncorhynchus mykiss). J Wildl Dis 26: 323-328.

5. Franco-Sierra A, Sitjà-Bobadilla A, Alvarez-Pellitero $P$ (1997) Ichthyophonus infections in cultured marine fish from Spain. J Fish Biol 51: 830-839.

6. Sindermann CJ (1970) Principal Disease of Marine fish and shellfish.

7. Neish GA, Hughes GC (1980) Fungal disease of fishes.

8. Sobecka E, Łuczak E, Marcinkiewicz M (2012) New cases of pathogens imported with ornamental Fish. J Bio Lett 49: 3-10.

9. Sindermann CJ (1990) Production. In: Principal Diseases of Marine Fish and Shellfish, Academic Press, New York.

10. Jones SRM, Dawe SC (2002) Ichthyophonus hoferi Plehn \& Mulsow in British Columbia stocks of Pacific herring. Clupea pallasi Valenciennes, and its infectivity to chinook salmon, Oncorhynchus tshawytscha (Walbaum). J Fish Dis 25: $415-421$.

11. Woo PTK, Btuno DW (2006) Fish Diseases and Disorders: viral, Bacterial and fungal infections. CAB International, London.

12. Humason GL (1979) Animal tissue techniques. WH Freeman and Company San Francisco.

13. McVicar AH, McLay HA (1985) Production. In: Fish and Shellfish Pathology, Tissue response of plaice, haddock and rainbow trout to the systemic fungus Ichthyophonus (ed. by Ellis AE). The Crown, London.

14. Mellergaard S, Spanggaard B (1997) An Ichthyophonus hoferi epizootic in herring in the North Sea, the Skagerrak, the Kattegat and the Baltic Sea. Dis aquat organ 28: 191-199.

15. McVicar AH (1982) Production. In: Ichthyophonus infections of fish, Microbial Disease of Fish Academic Press, London.

16. Rahimiyan H (1998) Pathology and morphology of Ichthyophonus hoferi in naturally infected fishes of the Swedish west coast. Dis Aquat Organ 34: 109123

17. Agius C (1979b) The role of melano-macrophage centers in iron storage in normal and diseased fish. J fish dis 2: 337-343.

18. Prabhuji SK, Sinha SK (2009) Life cycle (reproductive stages) of Ichthyphonus hoferi Plehn \& Mulsow, A Parasite Fungus causing Deep Mycoses in fish. The Int JPlant Reprod Biol 1: 93-101.

19. Sindermann CJ (1958) An epizootic in Gulf of Saint Lawrence fishes. Trans N Amer Wildl Conf 23: 349-360.

20. Ruggieri GD, Nigrelli RF, Powes PM, Garnett DG (1970) Epizootics in yellowtail flounder, Limanda ferrugineastorer, in the western north Atlantic caused by Ichthyophonus, an ubiquitous parasite fungus.

21. Donaldson EM (1981) Production. In: stress and fish, The pituitary-internal axis as an indicator of stress in fish (ed. by A.D. Pickering), Academic Press, Toronto, Ontario, Canada.

22. Spanggaard B, Huss HH (1996) Growth of the fish parasite Ichthyophonus 
Citation: Zadeh MJ, Peyghan R, Manavi SE (2014) The Detection of Ichthyophonus hoferi in Naturally Infected Fresh Water Ornamental Fishes. J Aquac Res Development 5: 289. doi:10.4172/2155-9546.1000289

Page 5 of 5

hoferi under food relevant conditions. Int J Food Sci Technol 31: 427-432.

23. Prabhuji SK, Srivastava GC, Sinha SK (1998) Observation on the histopathology of the vital organs of Carassius carassius, L. parasitized by Ichthyophonus hoferi, Plehnand Mulsow, Proc. National seminar on perspective in Aquatic Biology, Nainital.
24. Mhaisen FT, Al-Khateeb GH, Balasem AN, Al-Shaikh SMJ, Al-Jawda JM, et al. (2003) Occurrence of some fish parasites in AL-MADAEN drainage network south of Baghdad. Bull Iraq nat Hist Mus 10: 39-47.

25. Mansor NT, Falah AB, Al- Jawda JM, Asmar KR (2012) Histopathological study of some Tigris River fish which infected by parasites. The veterin $\mathrm{J}$ Iraq 36: $33-42$ 